Article

\title{
Economic Risk Assessment of Climate Change at the Urban Scale: The Case of Cape Town, South Africa
}

\author{
Martin P. de Wit ${ }^{1 *}$, Jonty Rawlins ${ }^{2}$ and Belynda Petrie ${ }^{3}$ \\ 1 Stellenbosch University, School of Public Leadership, Private Bag X1, Matieland, 7602, South Africa; \\ mdewit@sun.ac.za \\ 2 Sustainable Development Africa, Cape Town, South Africa; jrawlins@outlook.com \\ 3 OneWorld Sustainable Investments (OneWorld), PO Box 1777, Cape Town, 8001, South Africa; \\ belynda@oneworldgroup.co.za \\ * Correspondence: mdewit @sun.ac.za
}

\begin{abstract}
Estimating the economic risks of climate shocks and climate stressors on spatially heterogeneous cities over time remain highly challenging. The purpose of this paper is to present a practical methodology to assess the economic risks of climate change in developing cities to inform spatially sensitive municipal climate response strategies. Building on a capital-based framework $(\mathrm{CBF})$, spatially disaggregated baseline and future scenario scores for economic wealth and its exposure to climate change are developed for six different classes of capital and across 77 major suburbs in Cape Town, South Africa. Capital-at-risk was calculated by combining relative exposure and capital scores across different scenarios and with population impacted plotted against the major suburbs and the city's 8 main planning districts. The economic risk assessment presented here provides a generic approach to assist investment planning and the implementation of adaptation options through an enhanced understanding of relative levels of capital endowment vis-à-vis relative levels of exposure to climate-related hazards over time. An informed climate response strategy in spatially heterogeneous cities need to include spatially sensitive estimates on capital-at-risk and populations disproportionally impacted by climate exposure over time. The economic risk assessment approach presented here helps in advancing to such a goal.
\end{abstract}

Keywords: Economic risk assessment, capital-based framework, six-capital framework, climate response, climate adaptation, urban resilience 


\section{Author Biographies}

Martin de Wit is Professor: Environmental Governance at Stellenbosch University. He received his DCom degree at the University of Pretoria in 2001. His research is organised around an economic approach to environmental management and policy and follows an interdisciplinary approach with other experts in the fields of climate change, biodiversity and ecosystem services, waste management, energy transitions and ecological restoration. Martin serves as a regional coordinator for the African Association of Environmental and Resource Economists (AfAERE).

Jonty Rawlins is a sustainable development consultant and director at Sustainable Development Africa. He received an MSc in Water Science, Policy and Management from Oxford University in 2017 and an MSc in Economics from Rhodes University in 2016. His work and research are focused on practical and theoretical approaches to sustainable development and environmental management, with a particular focus on climate change, water resources management, biodiversity conservation, ecosystem services and equitable socio-economic development.

Belynda Petrie is co-founder and CEO of OneWorld Sustainable Investments and a PhD candidate at the University of Cape Town, where she is developing a thesis on regional integration and transboundary water governance and security. Her works spans policy and strategy developing in climate change response, water and energy security, and urban resilience, across Africa and Asia. She serves as a member of the Science Programme Committee for World Water Week and advises on climate finance on various boards, including the Alliance for Global Water Adaptation, and the recently launched Continental Africa Water Investment Programme. 


\section{Introduction}

Risk assessment of climate variability, climate change and natural disasters tend to focus on the hazards itself, exposure to the hazards and vulnerability to inform disaster risk management [1]. Climate change risk assessment focuses on the consequences, likelihood and responses to the impacts of climate change [2] and is conceptualized as a "fundamental interaction of the physical risk with the societal process of prioritizing, avoiding harm and making legitimate decisions" [2] (p.10). Economic assessments in urban contexts generally compare costs and benefits for the impacts of and responses to climate change, and have focused on specific risks such as flooding [3] and fire [4], on infrastructure development [5], on climate adaptation options [6,7] and on city policies to respond to climate change impacts [8]. Yet, of particular concern in this paper is how socioeconomic development at the full urban spatial scale is affected by climate change, and how this informs climate response strategies at the urban level - with specific reference to Cape Town. Scenario development is one approach that helps to construct narratives on impacts and costs for alternative futures under climate change, but lacks the detailed quantification of costs and spatial resolution needed for more directed responses [7]. As cities are confronted with a loss of economic wealth due to climate change impacts, economic risk assessments would theoretically require a probabilistic and spatially sensitive integrative modelling approach on an urban scale [9] - an approach especially relevant for spatially heterogenous, highly unequal and developing cities in emerging economies like Cape Town. Accounting for spatially sensitive interlinkages and indirect damages and losses in economic assessments on an urban level would require spatially sensitive macroeconomic tools, which in turn are reliant on updated input-output tables or social accounting matrices- all requirements that are not always readily available at an urban level [10], especially in developing cities. Published quantitative economic assessments of climate risk generally tend to focus on global, national or regional levels, with only a few studies attempting to examine climate risk at the urban scale [10]. Despite some progress, "...accurate quantitative assessment of city-specific climate change risk remains highly challenging" [10] (p. 10). The absence of sufficient data and of reliable quantitative economic assessment models at an urban scale, necessitates alternative practical approaches to support decision-making on climate change at the urban level.

City managers are faced with the question of how to allocate scarce resources over space and time across multiple competing priorities, including climate risks. Decisions have to be made in contexts of high spatial heterogeneity in biophysical impact and socio-economic vulnerability, and climate risks that may vary significantly over time. There is thus a need for a robust, practical and spatially sensitive screening tool that highlights the economic wealth-at-risk under various climate scenarios which can be used to inform climate response strategies. The approach followed here is to link model results on climate exposure at the urban level with various categories of capital indicators as approximations for a city's economic wealth. One of the challenges is to develop a realistic and balanced selection of indicators, which does bring issues of selection and weighing, but, as must be stated from the onset, for which there is "no scientifically valid solution" [11] (p 167).

A Hazard, Vulnerability and Risk Assessment (HVRA) conducted for Cape Town identified key climate driven risks (stressors and shocks) by modelling climate change indicators over time [12]. The assessment created a vulnerability index to determine different levels of risk and resilience across different spatial locations across Cape Town. Specifically, the HVRA anticipates a drier and warmer climate for the Cape Town, while the top climate-related hazards facing the city include drought, fire, heatwaves, floods and strong winds. The water supply system in the Western Cape Province, which supplies Cape Town with the majority of its bulk water requirements, faces significant risk from repeated drought events, with indirect impacts of a water availability crisis affecting the economy, environment and people of Cape Town. An earlier study on changes in rainfall and precipitation likewise included forecasts of a decrease in wet days, an increase in dry spells and a decrease in annual precipitation [13]. Combined with increased temperatures and evaporation, decreased water 
availability in the medium to long term is probable and changes to Cape Town's water resource management regime in the light of climate change is necessary and ongoing [14]. Moreover, fires pose a direct impact to human life and assets. Informal settlements are also more vulnerable to increased flooding and risk of fires given their location and limited access to services and resources [15]. The climate risk to Cape Town as a coastal city further includes sea-level rise which threatens infrastructure as well as the real estate and tourism industries [16]. With much of Cape Town's industrial, commercial and residential areas lying below $10 \mathrm{~m}$ above sea-level, sea-level rise increases the vulnerability of beaches and coastal developments in the city. Improved storm water strategies may be necessary as sea-level rise, storm surge and heavy rainfall are projected to exacerbate water pollution, compromise drinking water and damage coastal treatment plants [17].

While the nature and physical impact of climate shocks and stressors to a city have been determined using a HVRA, the quantification of economic risks of climate change remains necessary. The methodology proposed here is to follow a "capital-based framework" [18] (CBF) in support of an assessment of climate risks to the urban economy as a whole. The CBF overlaps with, but differs in many respects from the Capital Theory Approach (CTA) advanced in economic theory $[19,20]$, which has been developed into indicators for sustainability in its weak [21,22] and strong $[23,24]$ forms and promoted as a tool for sustainability policy $[25,26]$. In such a way of thinking the urban economy is portrayed in terms of the different types of capital (or assets) that provide a flow of benefits or services to the economy and society; that is they are defined as "productive assets available to the economy" [27] ( $p, 149)$. Sustainability is then defined as maintaining a constant aggregate capital stock over time $[20,28]$. The decision-rule to achieve sustainability would be that once capital is used to produce or consume, the rents (over and above an acceptable level of profit) should be re-invested to ensure that the same level of capital will be available for posterity. Questions on the relative importance of various categories of capitals in economic growth and development, and the substitutability between these capitals has dominated much of the literature on the CTA to sustainability and its critics $[27,28]$. In this paper we start with the same premise as in the CTA, namely that certain productive assets are available to the economy but argue for a more inclusive and comprehensive representation of all capital asset categories in advancing our ability to respond to climate risks in urban economies. As market prices often do not include the damages caused by excessive productivity in one capital category on others (e.g. environmental damage or decline in social fabric as a result of excessive financial accumulation or exploitative labour practices), market prices cannot be treated as a satisfactory benchmark for calculating the aggregate value for each type of capital. It follows that the relative importance of each of the capitals cannot singularly be derived from a particular model of the economy. Furthermore, as we are not following a modelling approach in this paper, the otherwise very important question on substitutability between the capitals over time is excluded from our analysis. Therefore, although there are important overlaps with the CTA, most notably that the stocks of capital need to be maintained over time to achieve sustainability, our approach cannot be categorized as such.

Our study applied a six capitals framework (financial, manufactured, human, intellectual, social, natural) to provide a holistic view of economic wealth at risk due to climate events and stressors. The six capitals framework has been developed conceptually in the field of integrated accounting [29] and applied in various forms in fields such as corporate social responsibility (CSR) [30] and rural development [31]. In the field of climate adaptation, multiple capital framework approaches have been applied to measuring coping and adaptive capacity in cities before [32].

The purpose of this paper is to develop a practical and spatially sensitive economic risk assessment approach to climate change at an urban scale. This will be achieved by developing a set of spatially sensitive indicators on six capitals at risk in an urban context, coupled with scenarios on how they are likely to be affected across various levels of climate exposure. We expect that the development of such an approach will enhance decision-making on climate risk at an urban scale, especially in cities characterized by large spatial and socio-economic inequalities. 


\section{Materials and Methods}

\subsection{Case study: Cape Town}

The city of Cape Town, located on the south-western tip of South Africa, is the country's second most populous city and the economic hub of the Western Cape Province (See Fig. 1 for a map). Cape Town is well-known for its harbour, natural environment (within the world-renowned Cape Floristic Region), and for landmarks such as Table Mountain and Cape Point. However, like most of South Africa, the socio-economic dynamics of Cape Town present a story of stark inequality. According to Statistics South Africa, almost $36 \%$ of the population of the city live below of the poverty line, with a dependency ratio in excess of $43 \%$ [33]. These inequalities manifest clearly in the spatial distribution of the population, a legacy of the Apartheid era spatial planning policies. Cape Town also faces a variety of climate change challenges including significant increases in temperature, long-term decreases in rainfall, changes in rainfall seasonality, more extreme heat days and heatwaves, and coastal erosion [12]. The combination of these climate change threats and the prevailing socio-economic dynamics present a complex risk scenario exacerbated by climate change.

Figure 1: Map of Cape Town

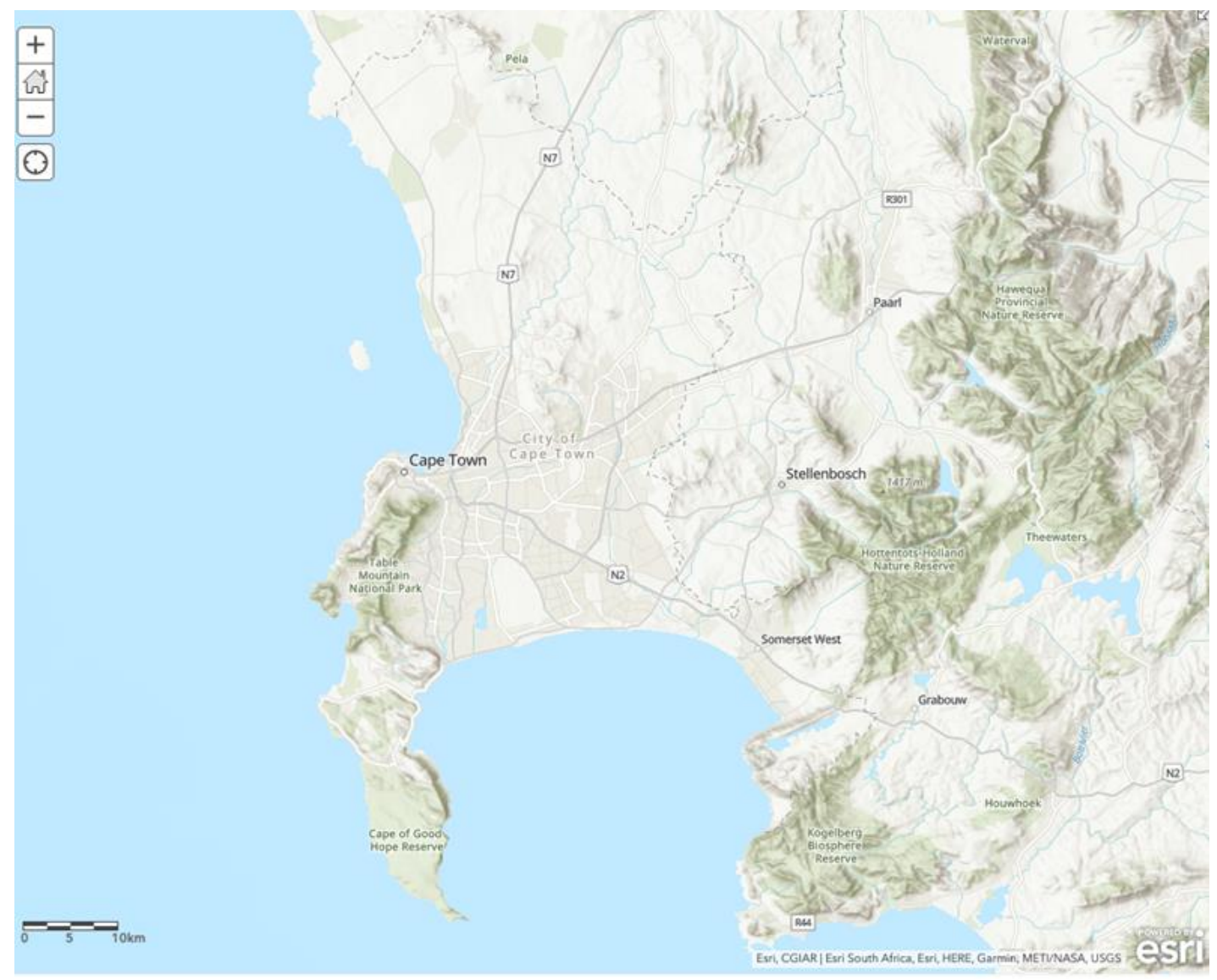

Source: Esri, CGIAR I Esri South Africa, Esri, HERE, Garmin, FAO, METI/NASA, USGS.

\subsection{Scenarios used}

Climate change related hazards occur at two distinct time scales, namely as events and disasters in the short term (climate shocks) and as gradual changes over longer time periods (climate stressors). Future risk pathways between climate change and the economy are conceptualized to include both climate exposure (incl. climate shocks and stressors) as well as 
projections of economic wealth at risk as measured on a scale of weakest to strongest indicators for each of the six capitals and their equally weighted aggregates. The outcome is that four spatially explicit scenarios are used to illustrate alternative futures for (i) high and low bound climate exposure and (ii) weak and strong capital projections.

\subsection{Indicators and data used}

The following six forms of capital are included in our economic risk assessment:

- Financial capital: The pool of funds available including debt, equity and grants generated through private and public operations and investments.

- Manufactured (durable) capital: Includes tools, machinery, buildings, equipment and other infrastructure (roads, bridges, ports, railways, and water and treatment plants).

- Human capital: Investment in skills, education and training determining the individual's competencies, capabilities, training and overall productivity.

- Intellectual capital: Intellectual property (patents, software, copyrights and licenses), organizational capital (tacit knowledge, protocols and systems) and other intangibles (city brand and reputation).

- Social capital: Institutions and customs organizing economic activity (shared norms, common values, non-physical culture, trust and willingness to engage).

- Natural capital: Natural systems including atmosphere, lithosphere, hydrosphere and biosphere.

Typical indicators and metrics for each of the six types of capitals were developed and are included in Appendix A. As not all indicators were equally well spatially developed in the City of Cape Town's databases, a representative set of indicators were tested and adopted with participants from the City of Cape Town's management. The main indicators that were selected and how they are measured for each capital category are included in Table 1.

\subsection{Economic Risk Assessment}

\subsubsection{Economic Risk Analysis Methodology}

Risk assessment traditionally involves an estimation of the magnitude of potential consequences or the levels of impacts, and the likelihood or the levels of probability of such impacts happening. The spatial and temporal extent of the risks can also be evaluated in such an assessment. We assessed economic risks based on the outcomes of results from the spatially explicit HVRA [12]. For each climate shock and stressor (or composite of such stressors and events, i.e. exposure) impacting on the capitals used in the economy, the economic risks needed to be assessed. The following stepwise approach was followed:

Step 1: Develop a "baseline" of capitals that are already functional in the city. The output in the productive economy is dependent on the well-functioning of these six categories of capitals as measured by selected indicators as indicated in Table 1 .

Table 1: Metrics and Projections for Six Capital Indicators

\begin{tabular}{lllll}
\hline Capital & Main Indicator(s) & Measure & \multicolumn{1}{l}{$\begin{array}{l}\text { Projections } \\
\text { (strong/weak) }\end{array}$} \\
\hline Financial & Total Revenue & $\begin{array}{l}\text { Total Budget } \\
\text { (Rands) }\end{array}$ & Expenditure & $\uparrow 2.4 \% ; \downarrow 2.4 \%$ \\
Human & Employment & \# of Employed People & $\uparrow 5 \% ; \uparrow 2 \%$ \\
\hline
\end{tabular}




\begin{tabular}{|c|c|c|c|}
\hline Natural & Ecosystem Functioning & Ecosystem Services Index & $\uparrow 3 \% ; \downarrow 3 \%$ \\
\hline \multirow[t]{2}{*}{ Social } & Crime Rate & \# of crimes & $\downarrow 2 \% ; \uparrow 2 \%$ \\
\hline & $\begin{array}{l}\text { Residential Property } \\
\text { Value }\end{array}$ & Mean Property Value (Rands) & $\uparrow 10 \% ; \uparrow 5 \%$ \\
\hline \multirow[t]{2}{*}{ Manufactured } & $\begin{array}{l}\text { Commercial and } \\
\text { Industrial Property Value }\end{array}$ & Mean Property Value (Rands) & $\uparrow 10 \% ; \uparrow 5 \%$ \\
\hline & $\begin{array}{l}\text { Access to Critical } \\
\text { Infrastructure }\end{array}$ & $\begin{array}{l}\text { Mean Travel Time to Hospitals } \\
\text { and Fire Stations (Minutes) }\end{array}$ & $\uparrow 2 \% ; \downarrow 2 \%$ \\
\hline Intellectual & Education Levels & $\begin{array}{l}\text { \# of People with Higher } \\
\text { Education }\end{array}$ & $\uparrow 3 \% ; \uparrow 1 \%$ \\
\hline
\end{tabular}

Note: ${ }^{*}$ An index value was used to represent natural capital rather than an individual lead indicator because of the variety of ecosystem types that function within the urban extent of Cape Town. This index represents a combination of ecosystem intactness and integrity indicators for biodiversity, forestry and watercourses and wetlands.

Step 2: Develop alternative futures for the capitals on a continuum of relatively weak capital functioning to strong capital functioning over time. Two future projections were generated for each capital indicator to represent a realistic 'strong' and 'weak' capital future. The last column in Table 1 illustrates the strong and weak projections for the six capital categories. The projections were based on historical trends for these variables and the extent of realistic worst case and best-case projections. The data used to represent each capital metric was projected until 2030 and normalized against a range from $0-1$, to ensure commensurability of the different metrics. An overall capital score was derived by equally weighing the six capital scores. To ensure spatial commensurability and to ensure that the spatial dimensions align closely with the approach followed in the HVRA, all capital scores were computed at the 'Major Suburb' level in Cape Town. A map of the 'Major Suburbs' in Cape Town is included in Appendix B (Normalized capital scores per major suburb are included in the Supplementary Material to this paper).

Step 3: Overlay projections on alternative climate change exposure futures with projections on alternative capital futures to identify areas where the economy, as measured through the indicators for capitals, is at relatively higher and lower risk in the short to medium future. The overall weighted capital score was combined with the medium term-future exposure index variables (derived from [12]) to indicate the areas where capital is most at risk within Cape Town. Table 2 outlines the different exposure variables that determines the exposure index, as well as approximated high and low bounds of uncertainty associated with mid-term future projections on these exposures. Uncertainty bounds were used to develop measures of high and low exposure for the mid-term future.

Table 2: Exposure Index Variables and Medium-Term Exposure Bounds

\begin{tabular}{lll}
\hline Exposure Variables & \multicolumn{2}{l}{ Medium Term Exposure } \\
\cline { 2 - 3 } Average, maximum and & High Bound & Low Bound \\
minimum temperature & $\uparrow 3^{\circ} \mathrm{C}$ & $\uparrow 1^{\circ} \mathrm{C}$ \\
Very hot days & $\uparrow 20$ Days & $\uparrow 0$ Days \\
Heat-wave days & $\uparrow 10$ Days & $\uparrow 0$ Days \\
High fire-danger days & $\uparrow 20$ Days & $\uparrow 0$ Days \\
Rainfall & $\downarrow 120 \mathrm{~mm}$ & $\downarrow 60 \mathrm{~mm}$ \\
Extreme rainfall & $\downarrow 3$ Days & $\downarrow 0$ Days \\
\hline
\end{tabular}

Source: Based on [12] 
Step 4: A combined capital and exposure assessment was undertaken for four different spatially explicit scenarios, namely:

- $\quad$ scenario 1: high bound climate exposure; weak capitals

- $\quad$ scenario 2: high bound climate exposure; strong capitals

- $\quad$ scenario 3: low bound climate exposure; weak capitals

- $\quad$ scenario 4: low bound climate exposure; strong capitals

\subsubsection{Capital-at-Risk}

Capital-at-Risk for each of the 'Major Suburbs' was derived by combining relative exposure and capital scores for all scenarios as per the following equation:

$$
\text { Capital-at-Risk }=\text { Exposure Score }{ }^{*} \text { Capital Score }
$$

\section{Results}

\subsection{Six Capitals Assessment}

Figure 2 shows the maps illustrating the aggregate result for the relative strength of all capital types across baseline, weak and strong capital projections for each of the 77 'Major Suburbs' in Cape Town. Appendix $C$ presents both the baseline capital and exposure scores classified from high to medium to low.

A broad pattern of higher baseline capital scores across the Western and Atlantic seaboards from Cape Farms North down to Cape Point occurs. In contrast, the central and eastern areas of Cape Town display generally lower capital scores. In future projections of weak and strong growth in the various capitals, the rank order of suburbs remains largely the same over time.

Figure 2: Baseline and Medium-Term Future Capital Scores by Major Suburb in Cape Town

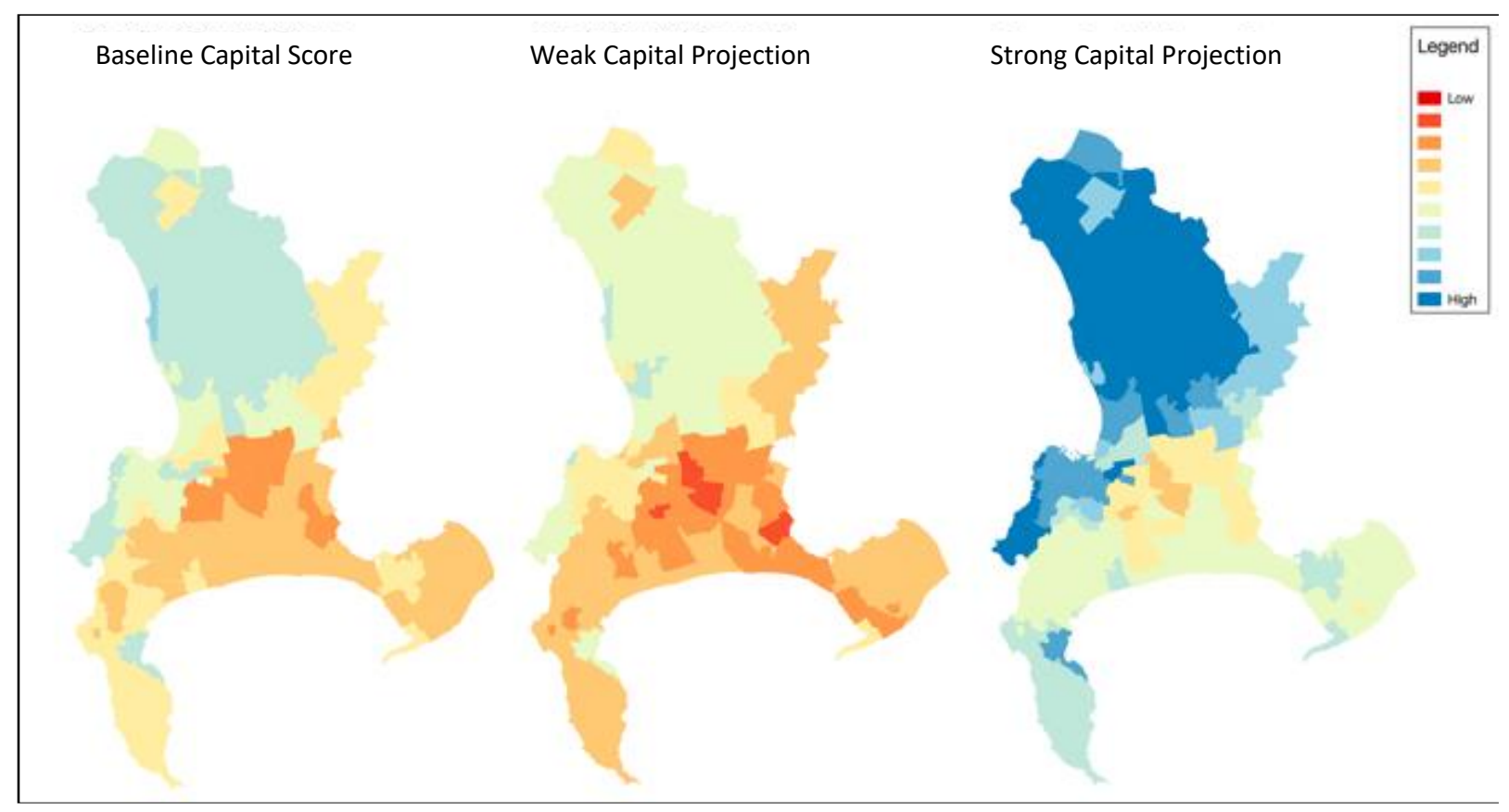


It is interesting to note which capitals score the highest in the various suburbs as depicted in Table 3. Much variation occurs between the types of capital that dominate in the various suburbs, highlighting the value of utilising a holistic six capital framework in the assessment.

Table 3: Top 5 baseline capital scores per suburb

\begin{tabular}{|c|c|c|c|c|c|}
\hline $\begin{array}{l}\text { Score } \\
\text { Rank }\end{array}$ & Human & Natural & Social & Manufactured & Intellectual \\
\hline 1 & Langa $(0,5)$ & $\begin{array}{l}\text { Table } \\
\text { Mountain } \\
(0,85)\end{array}$ & $\begin{array}{l}\text { Simons Town } \\
(0,8)\end{array}$ & $\begin{array}{l}\text { Observatory } \\
(0,72)\end{array}$ & Table View $(0,82)$ \\
\hline 2 & Delft $(0,35)$ & $\begin{array}{l}\text { Signall Hill/ } \\
\text { Lion's } \\
(0,82)\end{array} \quad$ & $\begin{array}{l}\text { Melkbosch } \\
\text { Strand }(0,56)\end{array}$ & Cape Town $(0,61)$ & Blouberg $(0,55)$ \\
\hline 3 & Gugulethu $(0,33)$ & $\begin{array}{l}\text { Cape Farms } \\
\text { South }(0,79)\end{array}$ & $\begin{array}{l}\text { Cape } \quad \text { Point } \\
(0,32)\end{array}$ & Sea Point $(0,61)$ & Plattekloof $(0,5)$ \\
\hline 4 & Blue Downs $(0,30)$ & $\begin{array}{l}\text { Cape } \\
(0,77)\end{array}$ & $\begin{array}{l}\text { Cape Farms } \\
\text { North }(0,17)\end{array}$ & Pinelands $(0,51)$ & $\begin{array}{l}\text { Rondebosch } \\
(0,43)\end{array}$ \\
\hline 5 & $\begin{array}{l}\text { Kalksteenfontein } \\
(0,30)\end{array}$ & $\begin{array}{l}\text { Camp's Bay } \\
(0,7)\end{array}$ & $\begin{array}{l}\text { Durbanville } \\
(0,16)\end{array}$ & $\begin{array}{l}\text { Paarden Eiland } \\
(0,5)\end{array}$ & Newlands $(0,42)$ \\
\hline
\end{tabular}

Note: Financial capital excluded (for full listing for each of capitals across the 77 major suburbs see the Supplementary Material).

\subsection{Climate Exposure Assessment}

Different capital stocks throughout Cape Town are exposed to relatively different levels of climate stressors and shocks in space and over time. Figure 3 depicts relative levels of exposure to climate change for the baseline and medium-term future projections respectively. It is important to note that the variance in climate exposure is relatively small in absolute terms across Cape Town. As with the aggregate capital scores, exposure is a function of multiple metrics which influence aggregate levels differently [12]. Broadly, the southern peninsula is less exposed while the central and eastern areas are more exposed. 
Figure 3: Baseline and Medium-Term Future Climate Exposure Scores by Major Suburb in Cape Town

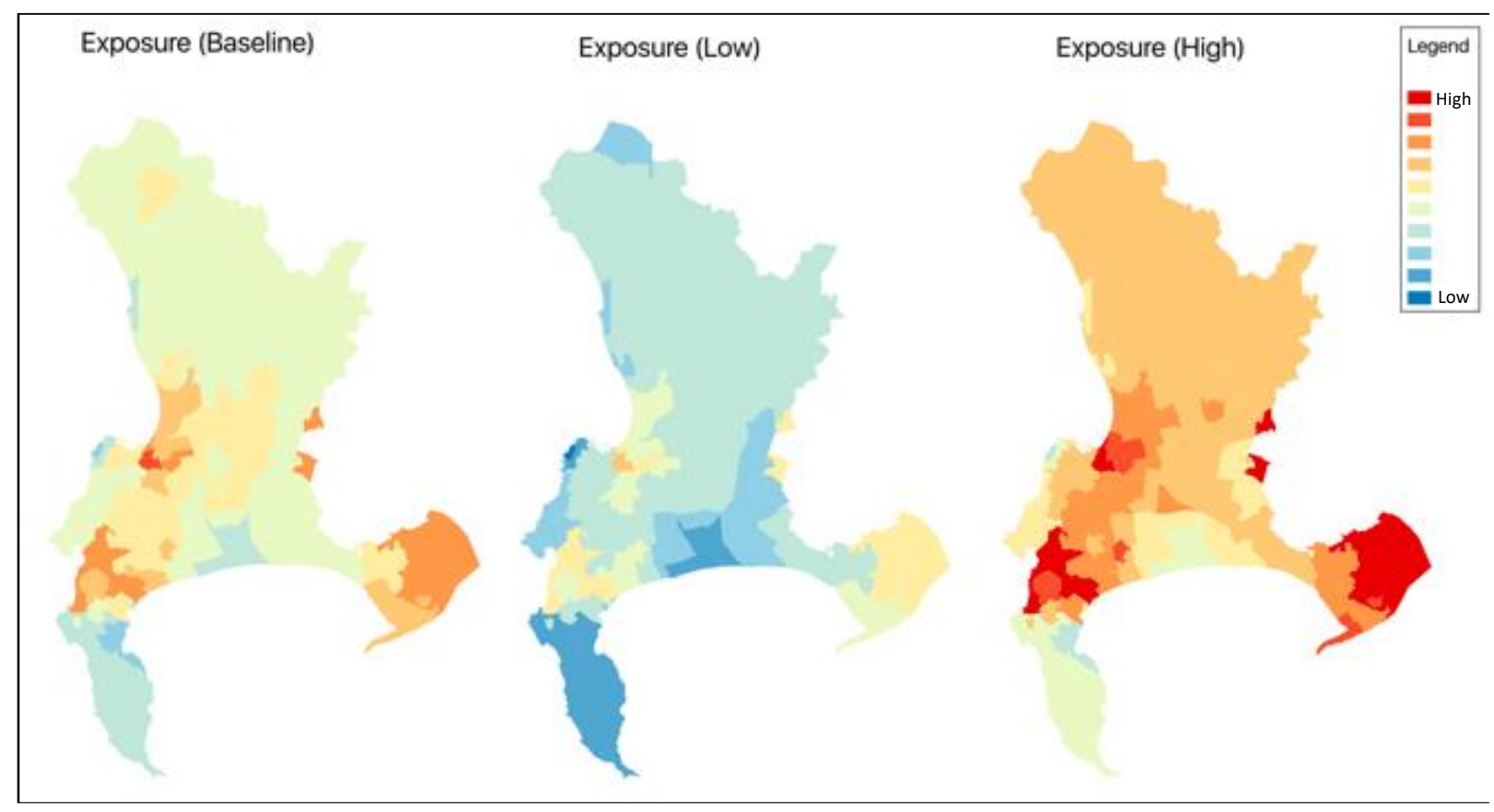

Note: The colour spectrum used to represent data was chosen to clearly illustrate small discrepancies in climate exposure.

\subsection{Capital-at-Risk}

Capital-at-Risk combined relative exposure and capital scores in one aggregate score (aggregate data and descriptive statistics are included in the Supplementary Material). The results for various scenarios are displayed in Figure 4, presenting the relative spatial distribution of four scenarios for combined capital and climate exposure scores. Highest capital-at-risk scores are on the Western and Atlantic seaboards from Cape Farms North down to Hout Bay and Simon's Town as well as Gordon's Bay in the east. In contrast, the central eastern areas of Cape Town display generally lower capital-at-risk scores. These scenarios represent the best and worst mid-term future positions based on currently available data. Intuitively, scenario 3 (weak capital growth and a low exposure to climate change) leads to the least risk to capital across the city, whilst scenario 4 (strong capital growth and a high exposure to climate change) leads to the greatest risk to capital. Appendix $C$ provides further detail on the baseline capital scores and exposure across each of the Major Suburbs in Cape Town.

Figure 4: Capital-at-Risk Across Capital and Exposure Scenarios 


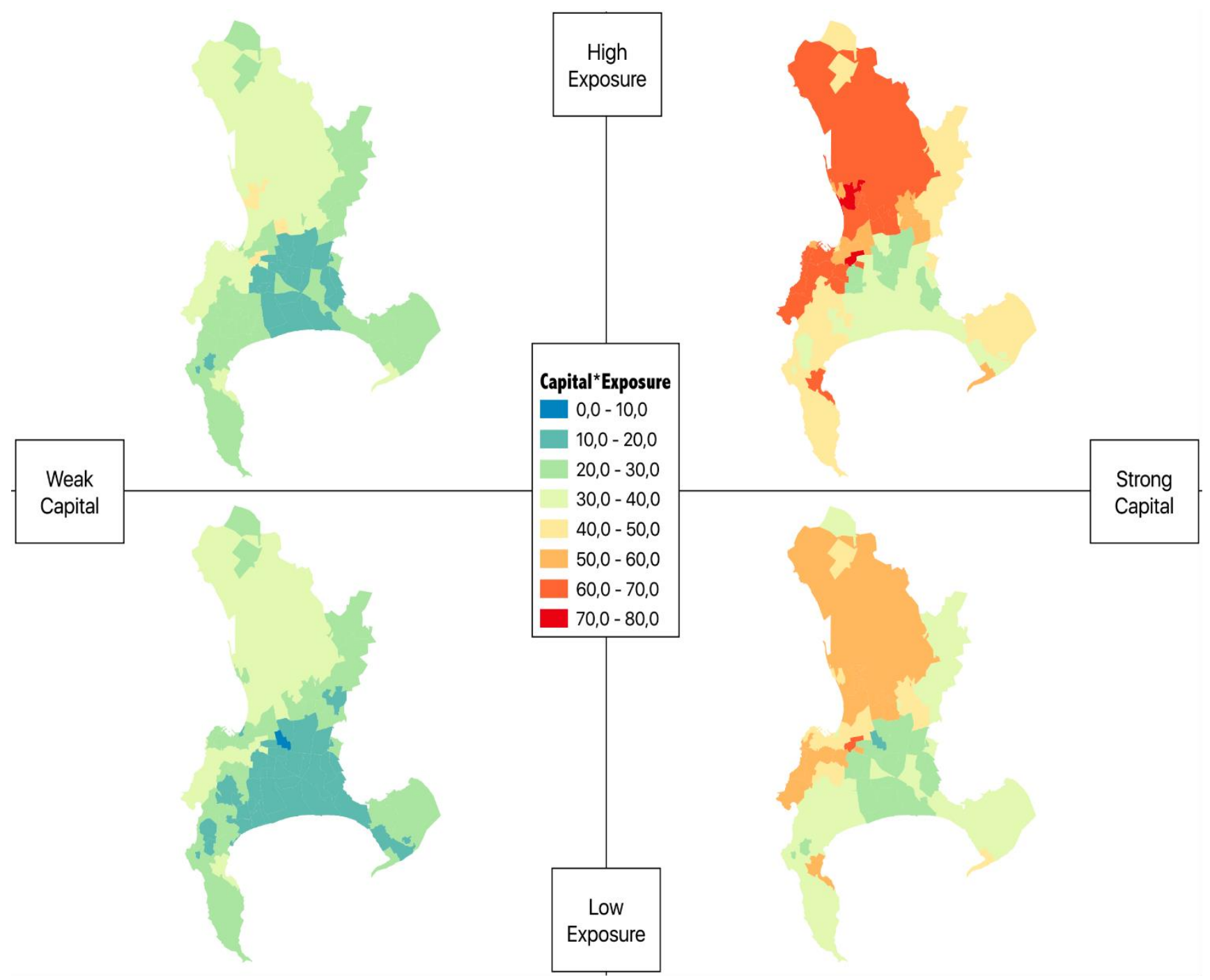

When explicitly disaggregating on a 'Major Suburb' level, Figure 5 presents Capital-at-Risk as a scatter plot of baseline capital scores and baseline levels of exposure to climate change. The size of the circles indicates relative population densities in each of the 77 'Major Suburbs' colour-coded for each of the 8 planning districts in the City of Cape Town. There is a clear general trend across the city showing areas of higher population (depicted by relatively larger circles) correlating with lower capital scores and medium to higher levels of exposure.

Figure 5: Capital-at-Risk by Major Suburb in Cape Town 


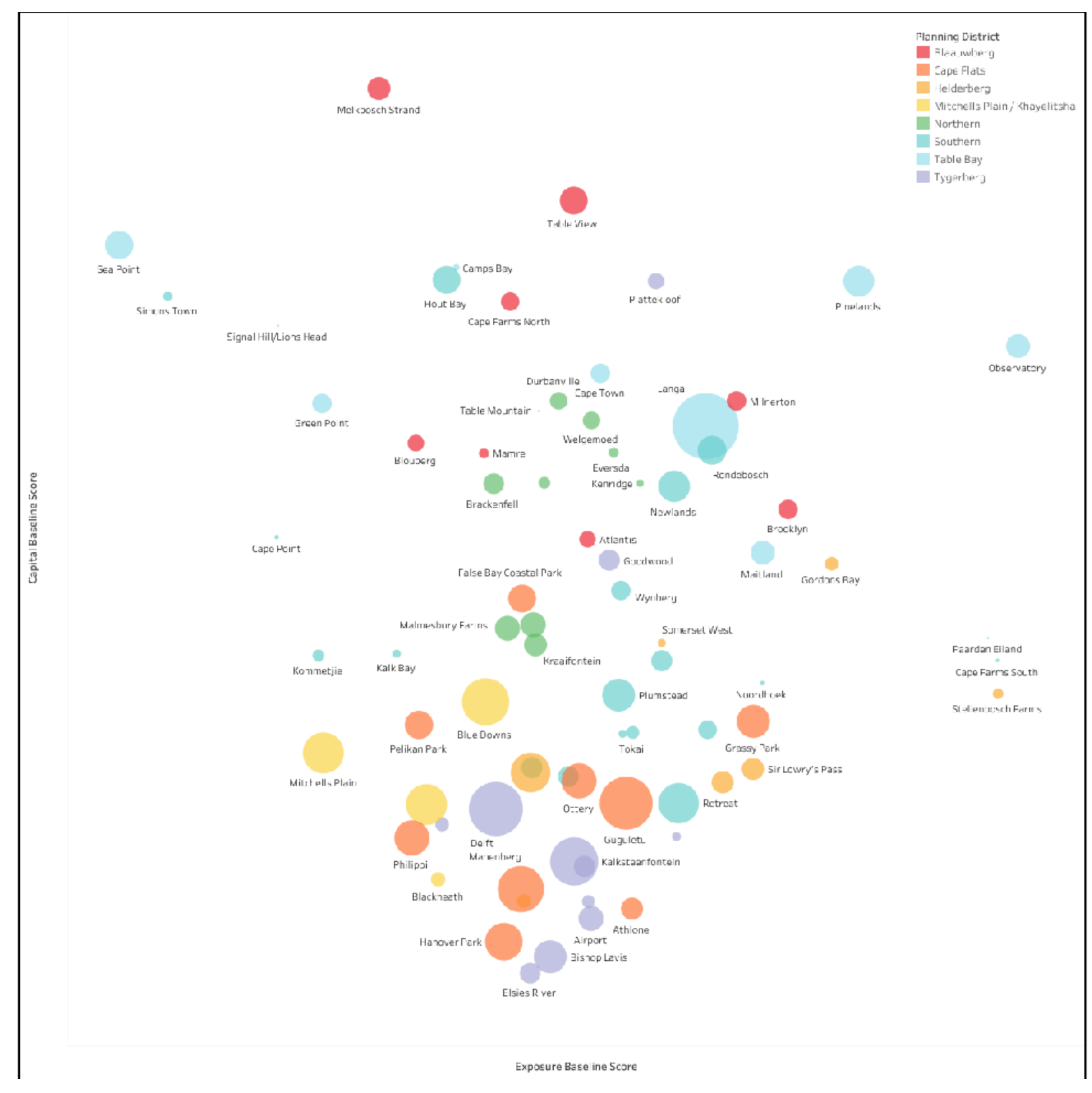

\section{Discussion and conclusion}

Accurate quantitative economic assessments of urban scale climate risk in spatially heterogeneous settings remains highly challenging. Our aim was to develop a practical and spatially sensitive approach to economic risk assessment of climate change at the urban scale that informs decision-making on climate responses in spatially heterogeneous cities - with specific reference to Cape Town. We believe that the approach presented here is conceptually simple, flexible and broadly implementable if (i) climate exposure is understood at the city scale and (ii) if spatial datasets on selected indicators for the six identified capitals are available across city delineations at sufficiently high resolution - in our case a listing of major suburbs and key planning districts. Assessing the economic risks of climate change over time is essential for an effective climate response strategy. The capital-at-risk analysis presented here is designed to provide a spatially robust departure point for more detailed assessments on how economic risks of climate change may manifest across space and time. The approach presented is based on best available climate modelling evidence of climate exposure at the Cape Town urban level [12] and the results have already been used as input to the 
formulation of Cape Town's climate response strategy [34]. Here we discuss the main results, highlight some of the limitations of our approach and make recommendations for future work.

Spatially the suburbs with the highest levels of capital generally have high levels of financial capital, but with much variation in the levels of manufactured, social, natural, human and intellectual capital (Table 3 and Supplementary Material). The suburbs with the highest baseline capital score are generally on the Western seaboard (geographically from Cape Farms North across Table View and Cape Town to Cape Point in the south). Manufactured capital scores are highest in areas all along this geographic area, namely Observatory, Cape Town CBD, Sea Point, Pinelands and Paarden Eiland. When the various capitals are analysed further several notable exceptions to this trend do appear though. The suburb of Langa has the highest human capital (number of employed people) of all the suburbs, but relative low levels of all other types of capital (except financial capital reflecting high levels of budget expenditure in this suburb). Delft, Gugulethu, Blue Downs and Kalksteenfontein are all suburbs geographically placed towards the entre of Cape Town and score low on overall capital scores, but are in the top 5 list of human capital in Cape Town. The highest natural capital scores in the city are to be found in suburbs spanning across Cape Town's iconic Table Mountain to Cape Point mountain range as well as on Cape Farms South, but also to the east at Stellenbosch Farms and Gordon's Bay. The highest intellectual capital in the city is in Table View and Blouberg, but also in other areas such as Plattekloof in Tygerberg and Rondebosch and Newlands in the Southern suburbs. Social capital tends to be relatively low in the city, with Simon's Town and Melkbosch Strand and to some extent Cape Point as notable exceptions. What these observations reveal is that capitals other than financial or manufactured capital are often distributed spatially differently.

The results on capital-at-risk on a major suburb level clearly indicate where currently the highest aggregate capital scores overlay with the highest relative climate exposure (upper right area in Figure 5). From an economic risk perspective these are the areas where capital-at-risk is the highest and which would accordingly inform a spatially sensitive climate response strategy. These areas coincide strongest with the Blaauwberg, Table Bay and Northern planning districts. As we have conceptualized a holistic vision of various capitals, it is insightful to note that certain areas with very high human capital (e.g. Langa) and certain areas with very high natural capital (Table Mountain) also come out as areas with medium to high capital-at-risk to climate exposure. Cape Farms South also has very high levels of natural capital, but lower overall capital baseline scores. As these examples illustrate, investing in the productive value of the economy to minimize risks of climate exposure would not only focus on protecting infrastructure and maintaining property values, but would also include investing in the workforce and in a city's natural assets.

Another important result illustrated in Figure 5 is that a people-centered approach to risk management would have to recognize not only the productive value of the economy (as measured through the capitals), but also the population at risk to climate shocks and stressors. In the spatially heterogeneous city of Cape Town, the results indicate that areas with relative higher population (indicated by larger circles) are correlated with lower overall capital scores and medium to high climate exposure (lower half in Figure 5). These areas coincide strongest with the Cape Flats, Tygerberg and Mitchell's Plain/Khayelitsha planning districts. The pattern is largely the result of South Africa's history of population separation which is still evident in population distributions and settlement patterns today. These areas have attracted relatively less investment in infrastructure, are often not formally planned and do not have access to much social or natural capital. Although government investment in these areas has been increasing over time (as measured by the financial capital indicator), these areas remain with infrastructure deficits and attract relatively little private investment. These areas also suffer from relatively higher levels of crime. Not surprisingly, many of these areas also exhibit low levels of overall resilience to climate change and other crises[12]. Increasing the resilience of a population to climate change is an important part of any climate response strategy, but on a practical level does raise issues for climate adaptation strategies aiming 
to be developmental and inclusive [34]. Our approach to view capital holistically rather than narrowly focused on financial or manufactured capital, is one attempt to ameliorate the gap between managing the risks to a productive economy and improving the resilience of the people. The "right kind of growth" and development is needed, namely an inclusive and resilient growth strategy that reduces the risks of and vulnerability to climate change [35]. For example, investments in property and infrastructure do need to recognize climate risks, as well as the viability of ecosystem based adaptations to climate change $[7,36]$.

Although a spatial assessment as presented here gives more granularity for planning purposes than what the sectoral or economy-wide approaches of macro-economic assessments would allow, a main limitation of our approach is that it does not account for the myriad of interlinkages and interdependencies which limit or reinforce the impacts of climate change throughout the economy. Climate change shocks such as floods, fires and heatwaves present immediate impacts to several economic activities in sectors as diverse as agriculture, transport and water \& electricity and with multiple risk pathways into the rest of the economy. A city economy is not fragmented in spatial suburban units but operate as an integrated system with linkages to regional, national and international economies. One of the implications is that it is not necessary for all suburbs to have equally high scores of all capital types as trade and exchange is a normal feature of wealth creation and risk management in a modern economy.

It is important to note that this analysis is designed to provide a departure point for more detailed assessments of how risks may manifest differently across space and time. For example, an area may exhibit high levels of capital-at-risk, but investigating the underlying data might reveal that the area is exposed only to expected increases in temperature, which could be ameliorated to a certain degree by investing in stronger natural capital through interventions such as ecological restoration [36,37]. Certain climate related risks would pose greater threats to different types of capital, for example fire would pose a significant risk to natural capital, and floods would pose a greater risk to manufactured capital such as infrastructure. Much more work remains in developing specific viable options to manage the economic risks of climate change in specific suburban contexts.

A key assumption of the Economic Risk Assessment is that the chosen leading indicators and/or composite indicators are representative of the specific capital distribution throughout the city. Although the indicators were tested with City of Cape Town's managers and the associated future scenarios are based on historical trends and scientific projections, the choice of indicator metrics was heavily influenced by available data at suitable spatial scales. Different cities may choose different indicators. A further limitation of the assessment presented here is the choice of indicator variable for financial and social capital. Total budget expenditure only represents the available financial capital available to the municipality and does not incorporate the productivity of the broader economy (e.g. private sector financial capital). Certain areas are invested in more by the municipality than others, these are often areas that experience service delivery deficits and are generally lower income areas. Thus, this may in some cases act to narrow the gap in aggregate scores between areas of higher capital and lower capital because higher investment in those areas is considered as a relatively higher financial capital score. Moreover, the inverse of the crime rate is a proxy for social capital in some respects, but this assumption is likely not to hold in all cases (e.g. higher rates of crime in some areas might result in improved social cohesion in response to the crime).

\section{Conclusions}

In conclusion, the practical and flexible methodology for economic risk assessment at an urban scale as presented here may especially hold value to city managers of spatially heterogeneous cities faced with climate change stressors and shocks now and in the foreseeable future. The expanded definition of capital introduced here allows for support of a growth and development strategy focused on productivity, inclusiveness and resilience of people to climate change. 


\section{References}

1. Walter, L.F. Climate Change and Disaster Risk Management; Springer: Berlin and Heidelberg, 2012.

2. Adger, W.N.; Brown, I.; Surminski, S.; Adger, W.N. Advances in risk assessment for climate change adaptation policy. Philos. Trans. A 2018, 376, 1-13, doi:https://doi.org/10.1098/rsta.2018.0106.

3. Zhou, Q.; Mikkelsen, P.S.; Halsnæs, K.; Arnbjerg-Nielsen, K. Framework for economic pluvial flood risk assessment considering climate change effects and adaptation benefits. J. Hydrol. 2012, 414-415, 539-549, doi:10.1016/j.jhydrol.2011.11.031.

4. Michael, Y.; Lensky, I.M.; Brenner, S.; Tchetchik, A.; Tessler, N.; Helman, D. Economic Assessment of Fire Damage to Urban Forest in the Wildland - Urban Interface Using Planet Satellites Constellation Images. Remote Sens. 2018, 10, 1-23, doi:10.3390/rs10091479.

5. Sharma, A.K.; Grant, A.L.; Grant, T.; Pamminger, F.; Opray, L. Environmental and economic assessment of urban water services for a greenfield development. Environ. Eng. Sci. 2009, 26, 921-934, doi:10.1089/ees.2008.0063.

6. Zhou, Q.; Halsnæs, K.; Arnbjerg-Nielsen, K. Economic assessment of climate adaptation options for urban drainage design in Odense, Denmark. Water Sci. Technol. 2012, 66, 1812-1820, doi:10.2166/wst.2012.386.

7. Cartwright, A.; Blignaut, J.; De Wit, M.; Goldberg, K.; Mander, M.; O’Donoghue, S.; Roberts, D. Economics of climate change adaptation at the local scale under conditions of uncertainty and resource constraints: The case of Durban, South Africa. Environ. Urban. 2013, 25, 139-156, doi:10.1177/0956247813477814.

8. Estrada, F.; Wouter Botzen, W.J.; Tol, R.S.J. A global economic assessment of city policies to reduce climate change impacts. Nat. Clim. Chang. 2017, 7, 403-408, doi:10.1038/NCLIMATE3301.

9. Lindley, S.J.; Handley, J.F.; Theuray, N.; Peet, E.; Mcevoy, D. Adaptation Strategies for Climate Change in the Urban Environment: Assessing Climate Change Related Risk in UK Urban Areas. J. Risk Res. 2007, 9, 543-568, doi:10.1080/13669870600798020.

10. Ye, B.; Jiang, J.; Liu, J.; Zheng, Y.; Zhou, N. Research on quantitative assessment of climate change risk at an urban scale : Review of recent progress and outlook of future direction. Renew. Sustain. Energy Rev. 2021, 135, 110415, doi:10.1016/j.rser.2020.110415.

11. Dahl, A.L. Integrated Assessment and Indicators. In Sustainability Indicators. A Scientific Assessment; Hák, T., Moldan, B., Dahl, A.L., Eds.; Island Press: Washington, Covelo, London, 2007; pp. 163-176.

12. Petrie, B.; Rawlins, J.; Engelbrecht, F.; Davies, R. Vulnerability and Hazard Assessment Report. Elaboration of a "Climate Change Hazard, Vulnerability and Risk Assessment"; OneWorld Sustainable Investments, Cape Town, South Africa, 2019.

13. Abiodun, B.J.; Adegoke, J.; Abatan, A.A.; Ibe, C.A.; Egbebiyi, T.S.; Engelbrecht, F.; Pinto, I. Potential impacts of climate change on extreme precipitation over four African coastal cities. Clim. Change 2017, 143, 399-413, doi:10.1007/s10584-017-2001-5.

14. City of Cape Town. Our Shared Water Future. Cape Town's Water Strategy; City of Cape Town, Cape Town, 2020.

15. Mukheibir, P.; Ziervogel, G. Framework for Adaptation to Climate Change in the City of Cape Town (FAC 4 T); City of Cape Town, Cape Town, 2006.

16. Colenbrander, D.; Cartwright, A.; Taylor, A. Drawing a line in the sand: Managing coastal risks in the City of Cape Town. South African Geogr. J. 2015, 97, 1-17, doi:10.1080/03736245.2014.924865.

17. Kessler, R. Stormwater strategies: cities prepare aging infrastructure for climate change. Environ. Health 
Perspect. 2011, 119, A514-A519, doi:10.1289/ehp.119-a514.

18. Wu, J.; Wu, T. Sustainability Indicators and Indices: An Overview. In Handbook of Sustainable Management; Madu, C.N.; Kuei, C. Eds.; Imperial College Press: London, 2012; pp. 65-86.

19. Solow, R.M. On the Intergenerational Allocation of Natural Resources. Scand. J. Econ. 1986, 88, 141-149, doi:10.2307/3440280.

20. Hartwick; M, J. Intergenerational Equity and the Investing of Rents from Exhaustible Resources. Am. Econ. Rev. 1977, 67, 972-974.

21. Hamilton, K.; Clemens, M. Genuine Savings Rates in Developing Countries. World Bank Econ. Rev. 1999, 13, 333-356.

22. Pearce, D.W.; Atkinson, G.D. Capital theory and the measurement of sustainable development: an indicator of "weak" sustainability. Ecol. Econ. 1993, 8, 103-108, doi:10.1016/0921-8009(93)90039-9.

23. Costanza, R.; Daly, H.E. Natural Capital and Sustainable Development. Conserv. Biol. 1992, 6, 37-46.

24. Ekins, P.; Simon, S.; Deutsch, L.; Folke, C.; De Groot, R. A framework for the practical application of the concepts of critical natural capital and strong sustainability. Ecol. Econ. 2003, 44, 165-185, doi:10.1016/S0921-8009(02)00272-0.

25. Tzachor, A. A capital theory approach should guide national sustainability policies. Cambridge J. Sci. Policy 2020, 1, 1-12.

26. Lange, G.-M.; Wodon, Q.; Carey, K. Building a Sustainable Future The Changing Wealth of Nations 2018; Washington D.C., 2018..

27. Stern, D.I. The Capital Theory Approach to Sustainability: A Critical Appraisal. J. Econ. Issues 1997, 31, 145-174, doi:10.1080/00213624.1997.11505895.

28. De Wit, M.P.; Blignaut, J.N. A critical evaluation of the capital theory approach to sustainable development. Agrekon 2000, 39, 111-125, doi:10.1080/03031853.2000.9523572.

29. Ardisa, A. The Six Capitals Framework. A Discussion of International Integrated Reporting Council's Model. Monash University, no date.

30. Fordham, A.E.; Robinson, G.M.; Cleary, J.; Dirk Blackwell, B.; Van Leeuwen, J. Use of a multiple capital framework to identify improvements in the CSR strategies of Australian resource companies. J. Clean. Prod. 2018, 200, 704-730, doi:10.1016/j.jclepro.2018.07.184.

31. Mikulcak, F.; Haider, J.L.; Abson, D.J.; Newig, J.; Fischer, J. Applying a capitals approach to understand rural development traps: A case study from post-socialist Romania. Land use policy 2015, 43, 248-258, doi:10.1016/j.landusepol.2014.10.024.

32. Tinch, R.; Jäger, J.; Omann, I.; Harrison, P.A.; Wesely, J.; Dunford, R. Applying a capitals framework to measuring coping and adaptive capacity in integrated assessment models. Clim. Change 2015, 128, 323337, doi:10.1007/s10584-014-1299-5.

33. Statistics South Africa. Local Municipality Statistics: City of Cape Town. Available online: http://www.statssa.gov.za/?page_id=993\&id=city-of-cape-town-municipality (accessed on Feb 25, 2021).

34. City of Cape Town. City of Cape Town Climate Change Strategy Draft for Public Participation; 2020.

35. Bowen, A.; Cochrane, S.; Fankhauser, S. Climate change, adaptation and economic growth. Clim. Change 2012, 113, 95-106, doi:10.1007/s10584-011-0346-8.

36. Prober, S.M.; Byrne, M.; McLean, E.H.; Steane, D.A.; Potts, B.M.; Vaillancourt, R.E.; Stock, W.D. Climateadjusted provenancing: A strategy for climate-resilient ecological restoration. Front. Ecol. Evol. 2015, 3, 1-5, doi:10.3389/fevo.2015.00065.

37. Bustamante, M.M.C.; Silva, J.S.; Scariot, A.; Sampaio, A.B.; Mascia, D.L.; Garcia, E.; Sano, E.; Fernandes, G.W.; Durigan, G.; Roitman, I.; et al. Ecological restoration as a strategy for mitigating and adapting to 
climate change: lessons and challenges from Brazil. Mitig. Adapt. Strateg. Glob. Chang. 2019, 24, 12491270, doi:10.1007/s11027-018-9837-5. 
Supplementary Materials: The following supplementary material is available online at www.mdpi.com/xxx: Table 1 - Exposure and Capital Data Descriptive Statistics .xlsx, Table 2 - Normalised Exposure and Capital Data.xlsx, Figure S1 - Baseline Capital Score Map.pdf, Figure S2 - Strong Capital Score Map.pdf, Figure S3 - Weak Capital Score Map.pdf, Figure S4 - Baseline Exposure Score Map.pdf, Figure S5 - High Exposure Score Map.pdf, Figure S6 - Low Exposure Score Map.pdf, Figure S7 - Exposure Capital Matrix.pdf, Figure S8 - Baseline Financial Capital Map.pdf, Figure S9 - Strong Financial Capital Map.pdf, Figure S10 - Weak Financial Capital Map.pdf, Figure S11 - Baseline Human Capital Map.pdf, Figure S12 - Strong Human Capital Map.pdf, Figure S13 - Weak Human Capital Map.pdf, Figure S14 - Baseline Intellectual Capital Map.pdf, Figure S15 - Strong Intellectual Capital Map.pdf, Figure S16 - Weak Intellectual Capital Map.pdf, Figure S17 - Baseline Manufactured Capital Map.pdf, Figure S18 - Strong Manufactured Capital Map.pdf, Figure S19 - Weak Manufactured Capital Map.pdf, Figure S20 - Baseline Natural Capital Map.pdf, Figure S21 - Strong Natural Capital Map.pdf, Figure S22 - Weak Natural Capital Map.pdf, Figure S23 - Baseline Social Capital Map.pdf, Figure S24 - Strong Social Capital Map.pdf, Figure S25 - Weak Social Capital Map.pdf

Author Contributions: The different contributions from the authors are as follows (MdW = Martin de Wit; JR = Jonty Rawlins; BP = Belynda Petrie): Conceptualization, MdW, JR and BP; Methodology, MdW and JR; Validation, MdW, JR and BP; Formal data analysis, JR and MdW; Investigation, MdW and JR; Resources, MdW and JR; Data curation, JR and MdW; Writing - original draft preparation, MdW and JR; Writing - review and editing, MdW, JR and BP; Visualization, JR; Supervision, MdW; Project administration, JR and BP; Funding acquisition, BP and JR. All authors have read and agreed to the published version of the manuscript.

Funding: This research was funded by the Agence Française de Développement (AFD) for the benefit of the City of Cape Town, grant number AFD: CZZ2197/MS/2017/03, under the project Accord-Cadre de prestations d'études et d'assistance technique pour l'initiative Villes et Changement climatique en Afrique subsaharienne (CICLIA), AFD/DOE/EBC/CLD I ACH-2017-026.

Acknowledgments: The authors would like to acknowledge Amy Davison of the City of Cape Town (Head Climate Change - Environmental Management Department) for her immeasurable support of this project and research, including overall project coordination, facilitating data access and stakeholder engagement, and verifying and validating the findings and outputs.

Conflicts of Interest: The authors declare no conflict of interest. 
Appendix A: Indicators for the six types of capital

\begin{tabular}{|c|c|c|}
\hline Capital Type & Indicator & Data/ Measurement \\
\hline \multirow{2}{*}{ Financial } & Operating cost (actual/budget) of city & $\begin{array}{l}\text { Service charges, property rates, government } \\
\text { grants, other own revenue, investment revenue }\end{array}$ \\
\hline & Capital costs (actual/budget) of city & $\begin{array}{l}\text { Borrowing, internally generated funds, national } \\
\text { grants, provincial grants, public donations }\end{array}$ \\
\hline \multirow{4}{*}{ Manufactured } & $\begin{array}{l}\text { Areas and property values over various } \\
\text { built environment categories (e.g. } \\
\text { commercial, industry, residential) }\end{array}$ & $\begin{array}{l}\text { Median freehold residential property values, } \\
\text { properties by suburb ( } 770 \text { units) and value band }\end{array}$ \\
\hline & Roads, bus-roads, railways & Kilometres of roads, bus-roads, railways \\
\hline & Vehicles over various categories & Number of households with motorcars \\
\hline & Critical infrastructure & $\begin{array}{l}\text { Proxy of travel time to critical infrastructure and } \\
\text { service centres (e.g. fire departments, police } \\
\text { stations) }\end{array}$ \\
\hline \multirow{5}{*}{ Human } & Economically active population & $\begin{array}{l}\text { Number employed, unemployed, discouraged } \\
\text { and non-active persons }\end{array}$ \\
\hline & $\begin{array}{l}\text { Indicators of (un)employment, poverty } \\
\text { and inequality }\end{array}$ & $\begin{array}{l}\text { Number (un)employed, median household } \\
\text { income, income range by suburb, households } \\
\text { with cell phone/internet access }\end{array}$ \\
\hline & $\begin{array}{l}\text { Educational attainment across age } \\
\text { groups }\end{array}$ & $\begin{array}{l}\text { Percentage of population with no schooling } \\
\text { (aged } 20+) \text {, with matric }(20+) \text {, with higher } \\
\text { education }(20+)\end{array}$ \\
\hline & Health indices & $\begin{array}{l}\text { Pneumonia incidence and malnutrition incidence } \\
\text { (under 5), hepatitis A incidence, typhoid } \\
\text { incidence, HIV incidence, percentage positive TB } \\
\text { tests }\end{array}$ \\
\hline & Informal settlements & Percentage area of informality \\
\hline \multirow{5}{*}{ Intellectual } & Size of knowledge sector & Number of people with higher education \\
\hline & $\begin{array}{l}\text { Money spent on research and } \\
\text { development }\end{array}$ & $R \& D$ as percentage of GDP \\
\hline & Brand awareness & Brand perception \\
\hline & Science outputs & Number of publications \\
\hline & $\begin{array}{l}\text { Number and value of knowledge, } \\
\text { technology patents }\end{array}$ & Number of patents \\
\hline \multirow{7}{*}{ Natural } & Area of land across natural categories & $\begin{array}{l}\text { Area of land declares urban conservation areas, } \\
\text { as nature reserves, as urban conservation areas, } \\
\text { designated as wetland }\end{array}$ \\
\hline & Water stocks and use & Average monthly household water use \\
\hline & $\begin{array}{l}\text { Measures of biodiversity integrity and } \\
\text { resilience }\end{array}$ & $\begin{array}{l}\text { Percentage of suburb area that are critical } \\
\text { biodiversity and protected areas }\end{array}$ \\
\hline & Pollution metrics & Water, air and solid pollution \\
\hline & Waste metrics & $\begin{array}{l}\text { Percentage of households with no rubbish } \\
\text { collection }\end{array}$ \\
\hline & Ecosystem services metrics & SANBI ecosystem status (mean) \\
\hline & $\begin{array}{l}\text { Valuation of environmental quality of air, } \\
\text { land, water, biological systems }\end{array}$ & Value of ecosystem services \\
\hline \multirow[t]{2}{*}{ Social } & $\begin{array}{l}\text { Measures of trust, reciprocity and } \\
\text { cohesion }\end{array}$ & Racial integration index \\
\hline & Indicators of livelihoods and dependency & Household dependency ratio \\
\hline
\end{tabular}


Number of street people

Metrics of involvement in social and cultural initiatives

Metrics of citizen satisfaction

Metrics of social wellbeing
Number of early childhood development forums

Percentage of people who voted for governing party

Number of service requests lodged

Access to piped water, electricity

Housing owned/paid off

Population density

Incidences of crime

\section{Appendix B: Locality of the 77 'Major Suburbs' in Cape Town}
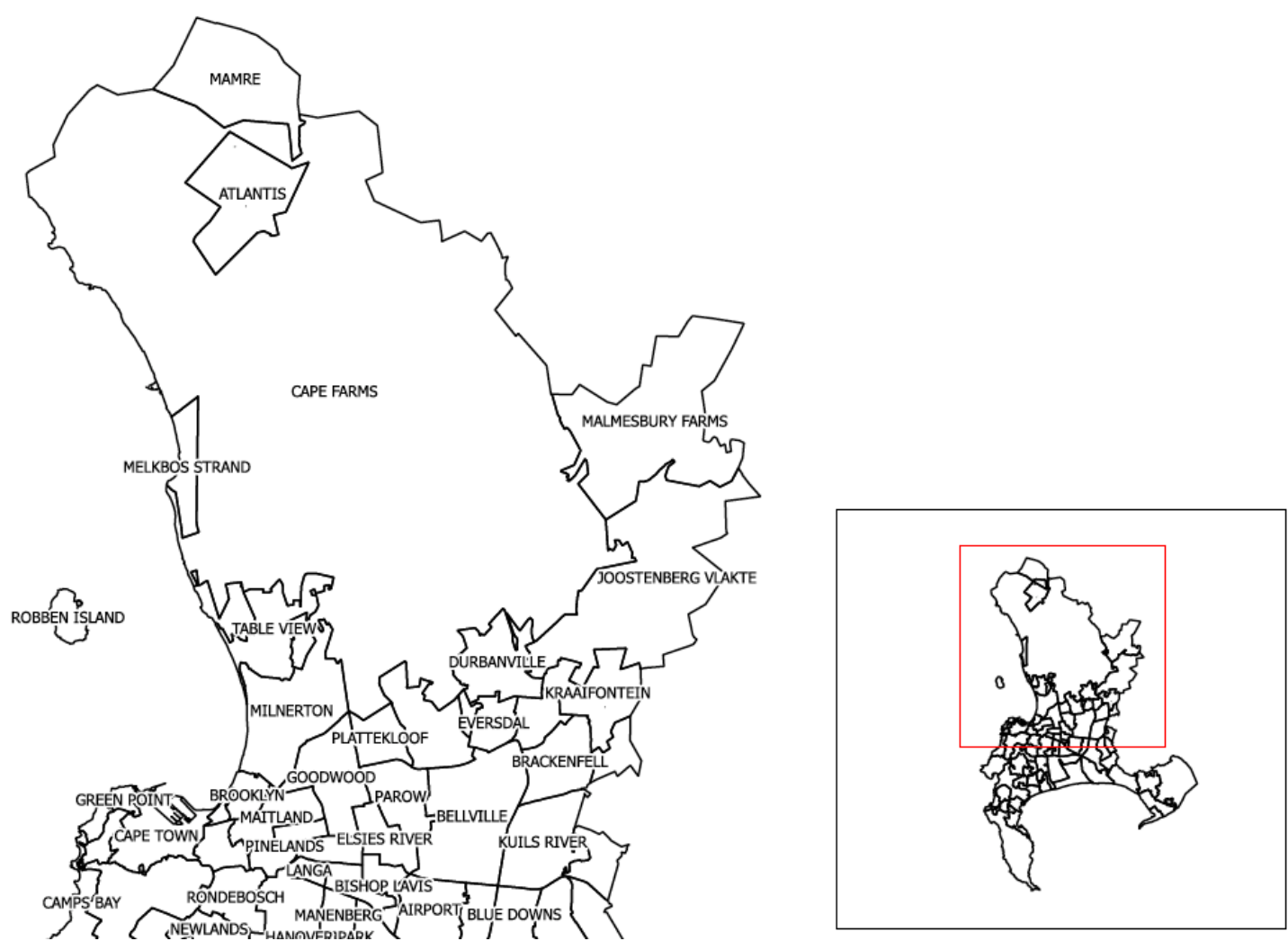

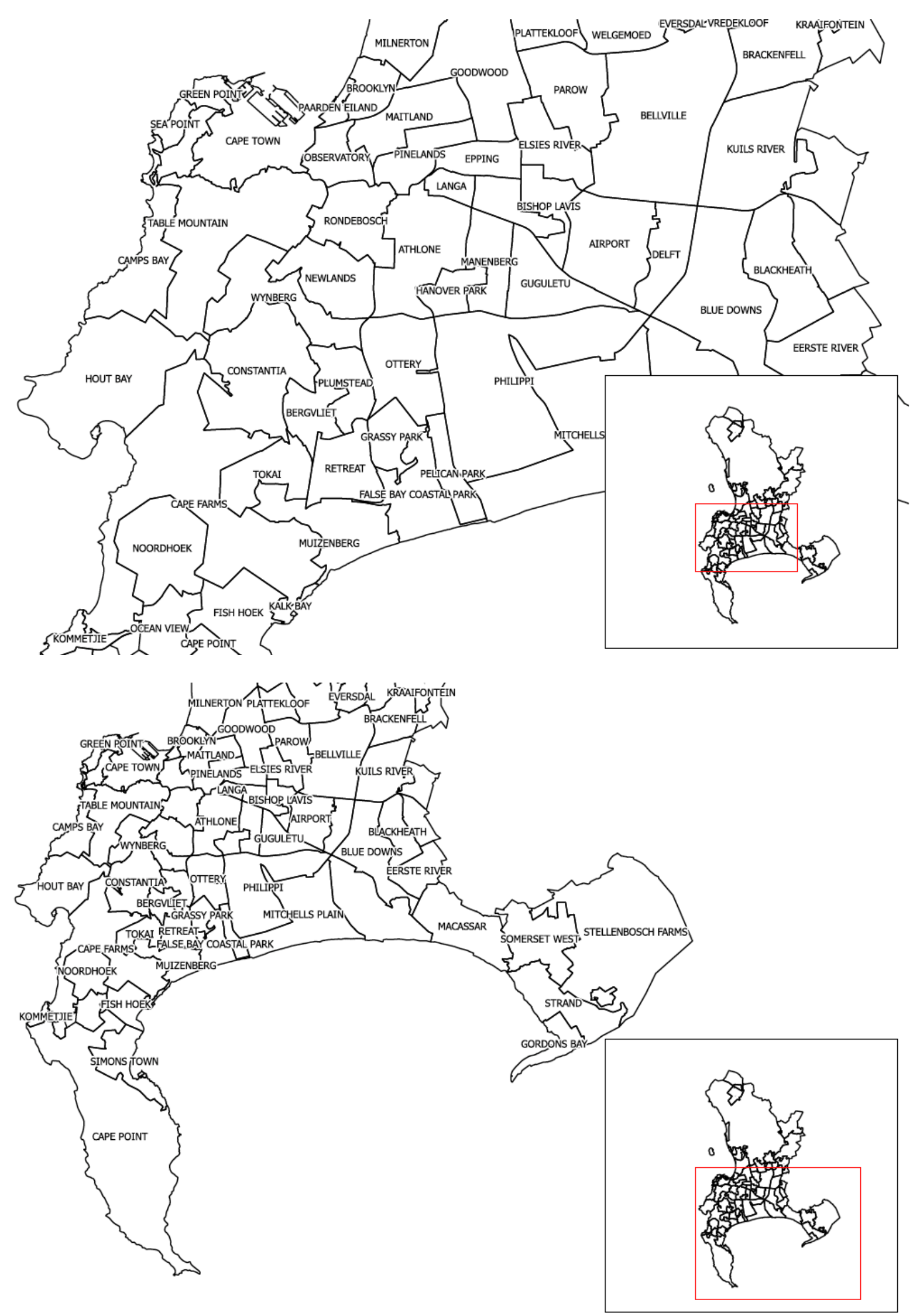


\section{Appendix C: Capital Scores and Exposure across 77 Major Suburbs in Cape Town}

Further detail on the relative baseline capital scores and exposure across Major Suburbs in Cape Town is provided here. The scores are determined as follows:

- High $>75^{\text {th }}$ percentile

- $\quad$ Medium $<75^{\text {th }}$ percentile $\&>25^{\text {th }}$ percentile

- $\quad$ Low $<25^{\text {th }}$ percentile

\begin{tabular}{|c|c|c|}
\hline Major Suburb & Baseline Capital & Baseline Exposure \\
\hline AIRPORT & Low & Medium \\
\hline ATHLONE & Low & Medium \\
\hline ATLANTIS & Medium & Medium \\
\hline BELLVILLE & Low & Medium \\
\hline BERGVLIET & Medium & Medium \\
\hline BISHOP LAVIS & Low & Medium \\
\hline BLACKHEATH & Low & Low \\
\hline BLOUBERG & High & Low \\
\hline BLUE DOWNS & Medium & Low \\
\hline BRACKENFELL & Medium & Low \\
\hline BROOKLYN & Medium & High \\
\hline CAMPS BAY & High & Low \\
\hline CAPE FARMS NORTH & High & Medium \\
\hline CAPE FARMS SOUTH & Medium & High \\
\hline CAPE POINT & Medium & Low \\
\hline CAPE TOWN & High & Medium \\
\hline CONSTANTIA & Medium & Medium \\
\hline DELFT & Low & Medium \\
\hline DURBANVILLE & High & Medium \\
\hline EERSTE RIVER & Low & Medium \\
\hline ELSIES RIVER & Low & Medium \\
\hline EPPING & Low & High \\
\hline EVERSDAL & Medium & Medium \\
\hline FALSE BAY COASTAL PARK & Medium & Medium \\
\hline FISH HOEK & Medium & Medium \\
\hline GOODWOOD & Medium & Medium \\
\hline GORDONS BAY & Medium & High \\
\hline GRASSY PARK & Medium & High \\
\hline GREEN POINT & High & Low \\
\hline GUGULETU & Low & Medium \\
\hline HANOVER PARK & Low & Medium \\
\hline HOUT BAY & High & Low \\
\hline JOOSTENBERG VLAKTE & Medium & Medium \\
\hline
\end{tabular}




\begin{tabular}{|c|c|c|}
\hline KALK BAY & Medium & Low \\
\hline KALKSTEENFONTEIN & Low & Medium \\
\hline KENRIDGE & Medium & Medium \\
\hline KHAYELITSHA & Low & Low \\
\hline KOMMETJIE & Medium & Low \\
\hline KRAAIFONTEIN & Medium & Medium \\
\hline KUILS RIVER & Low & Low \\
\hline LANGA & High & High \\
\hline MACASSAR & Medium & Medium \\
\hline MAITLAND & Medium & High \\
\hline MALMESBURY FARMS & Medium & Medium \\
\hline MAMRE & Medium & Low \\
\hline MANENBERG & Low & Medium \\
\hline MELKBOSCH STRAND & High & Low \\
\hline MILNERTON & High & High \\
\hline MITCHELLS PLAIN & Medium & Low \\
\hline MUIZENBERG & Medium & High \\
\hline NEWLANDS & Medium & High \\
\hline NOORDHOEK & Medium & High \\
\hline OBSERVATORY & High & High \\
\hline OCEAN VIEW & Medium & Medium \\
\hline OTTERY & Low & Medium \\
\hline PAARDEN EILAND & Medium & High \\
\hline PAROW & Low & Medium \\
\hline PELIKAN PARK & Medium & Low \\
\hline PHILIPPI & Low & Low \\
\hline PINELANDS & High & High \\
\hline PLATTEKLOOF & High & Medium \\
\hline PLUMSTEAD & Medium & Medium \\
\hline RETREAT & Low & High \\
\hline RONDEBOSCH & High & High \\
\hline SEA POINT & High & Low \\
\hline SIGNAL HILL/LIONS HEAD & High & Low \\
\hline SIMONS TOWN & High & Low \\
\hline SIR LOWRY'S PASS & Medium & High \\
\hline SOMERSET WEST & Medium & High \\
\hline STELLENBOSCH FARMS & Medium & High \\
\hline STRAND & Low & High \\
\hline TABLE MOUNTAIN & High & Medium \\
\hline TABLE VIEW & High & Medium \\
\hline
\end{tabular}




\begin{tabular}{lcc} 
TOKAI & Medium & Medium \\
VREDEKLOOF & Medium & Medium \\
WELGEMOED & High & Medium \\
WYNBERG & Medium & Medium \\
\hline
\end{tabular}

